\title{
A importância dos acidentes ofídicos como causa de mortes em bovinos no Brasil ${ }^{1}$
}

\author{
Carlos Hubinger Tokarnia² e Paulo Vargas Peixoto²
}

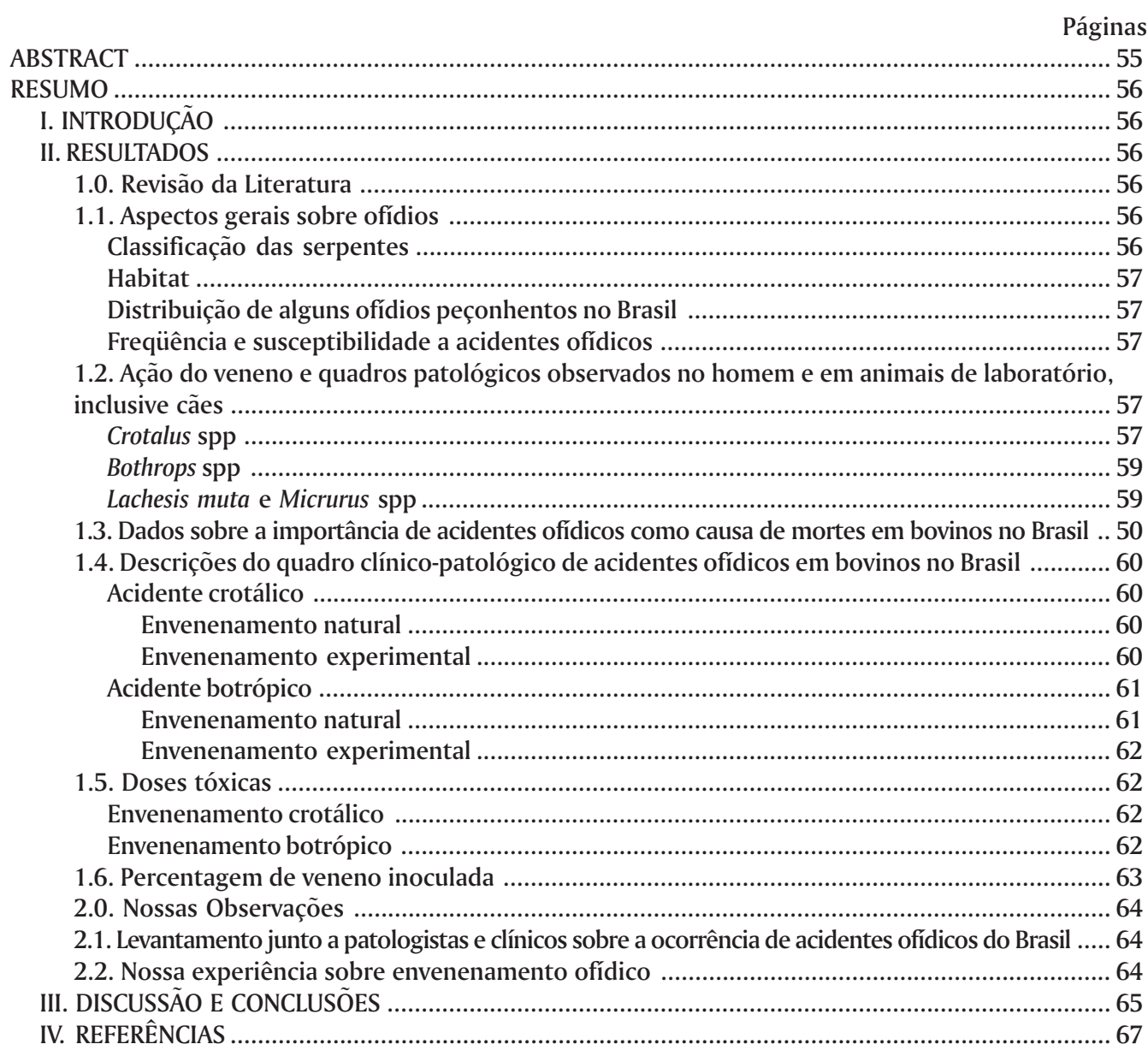

ABSTRACT.- Tokarnia C.H. \& Peixoto P.V. 2005. [The importance of snake bites as cause of cattle death in Brazil.] A importância dos acidentes ofídicos como causa de mortes em bovinos no Brasil. Pesquisa Veterinária Brasileira 26(2):55-68. Projeto Sanidade Animal Embrapa/UFRRJ, Km 47, Seropédica, RJ 23890-000, Brazil.E-mail: tokarnia@ufrrj.br

A review of the literature shows that opinions on the importance of snake bites as cause of cattle death in Brazil are divergent among veterinarians; some think they are of no importance or of only minor significance, others are of the opinion that snake bites are frequent. However, the

1 Recebido em 3 de agosto de 2005.

Aceito para publicação em 10 de setembro de 2005 .

\footnotetext{
2 Depto Nutrição Animal e Pastagem, Instituto de Zootecnia, Universidade Federal Rural do Rio de Janeiro (UFRRJ), Seropédica, RJ 23890-000. E-mail: tokarnia@uffrj.br, peixotop@ufrrj.br
} 
literature only reports two confirmed fatal cases by Bothrops and none by Crotalus in cattle in the country. A questionnaire which was submitted for appraisal to veterinary pathologists and clinicians in various States of Brazil, revealed only suspected cases of fatal accidents by snakes in cattle. During our field and laboratory diagnostic work we never made a diagnosis of a snake bite accident. Many "diagnoses" have apparently been made at a distance from where the animals died, without clinical and post-mortem examination, nor histological studies. By this way, the great majority of cases seems to be only supposition.

In Brazil there are only few snakes of the genus Bothrops theoretically able to produce sufficient amounts of venom to kill an adult bovine. Nevertheless, in experiments, only Bothrops alternatus was able to cause the death of just one out of three bovines bitten, and this animal only weighed $279 \mathrm{~kg}$. Snakes of the genus Crotalus can produce sufficient amounts of venom to kill an adult bovine; however it is known, that snakes of the genus Crotalus as well as of Bothrops generally inoculate only a part of their venom.

These considerations indicate that the deaths suspected to have been caused by snake bites in cattle in Brazil have to be studied more thoroughly. A diagnosis can only be confirmed by establishing the precise clinical and pathological picture. Our current opinion is that fatal snake bites are much less frequent in cattle than often believed, and that their importance is generally much exaggerated.

INDEX TERMS: Snake bites, snakes, Crotalus spp, Bothrops spp, cattle.

RESUMO.- A revisão da literatura pertinente indica que as opiniões sobre a importância dos acidentes ofídicos, como causa de mortes em bovinos no Brasil, são divergentes no meio veterinário. Enquanto alguns acreditam que são pouco importantes, ou que têm menor significado do que lhes é atribuído, outros são da opinião que esses acidentes são freqüentes. Verificou-se que só foi relatado diagnóstico fundamentado de dois casos fatais de envenenamento por Bothrops spp em bovinos, e de nenhum por Crotalus spp. Um questionário por nós submetido a patologistas e clínicos veterinários que atuam em diversos Estados do país, revelou apenas raros casos suspeitos de envenenamento ofídico fatal em bovinos no Brasil. Em nossas viagens de estudo e nos trabalhos de diagnóstico nunca estabelecemos o diagnóstico de morte por acidente ofídico em bovinos. Os casos tidos como envenenamento ofídico, na sua grande maioria, são apenas suposições, sem embasamento. Esses "diagnósticos", em geral, são feitos à distância dos animais que morreram, à revelia de exame clínico, necropsia e estudo histopatológico. Importante foi a constatação de que, no Brasil, embora algumas serpentes do gênero Bothrops possam, teoricamente, produzir quantidades suficientes de veneno para matar um bovino adulto, em experimentos realizados, apenas Bothrops alternatus foi capaz de levar a morte um dos três bovinos experimentalmente por ela picados; esse animal tinha apenas $279 \mathrm{~kg}$. Já as serpentes do gênero Crotalus poderiam inocular quantidades letais de veneno para bovinos adultos. Mesmo assim, tanto para Bothrops spp, como para Crotalus spp, há que se considerar que as serpentes, em geral, só inoculam parte do veneno disponível. Esse estudo indica que é necessário melhor investigar as mortes suspeitas de terem sido causadas por acidente ofídico em bovinos no Brasil. O estabelecimento do diagnóstico de morte por envenenamento ofídico, porém, só é possível pela determinação precisa do quadro clínico-patológico. Com base nos dados disponíveis e em nossa experiência, somos da opinião que os acidentes ofídicos fatais em bovinos são bem menos freqüientes do que se acredita, isto é, sua importância vem sendo bastante superestimada.
TERMOS DE INDEXAÇÃO: Acidente ofídico, serpentes, Crotalus spp, Bothrops spp, bovinos.

\section{INTRODUÇÃO}

No Brasil, tanto por parte dos veterinários, como dos fazendeiros e vaqueiros é muito comum, principalmente em bovinos, a prática de atribuir a acidentes ofídicos as mortes de etiologia desconhecida ou causadas por outros agentes. Essa assertiva é ainda mais freqüente nas diversas áreas onde ocorrem intoxicações por plantas que causam morte súbita (Tokarnia et al. 2000). Não há dúvida que envenenamentos ofídicos ocorrem, porém, até que ponto eles podem ter importância como causa de morte em bovinos, é algo que precisa ser determinado. Assim sendo, este estudo tem o objetivo de levantar as evidências sobre esses acidentes em bovinos, na tentativa de estabelecer sua real importância como causa de prejuízos econômicos no Brasil.

\section{RESULTADOS 1.0. REVISÃO DA LITERATURA}

\section{Classificação das serpentes \\ 1.1. Aspectos Gerais sobre Ofídios}

Segundo Barraviera \& Pereira (1994) existem, no mundo, aproximadamente 3 mil espécies de serpentes, das quais apenas 410 são consideradas venenosas. No Brasil estão catalogadas, até o momento, 256 espécies, sendo 69 venenosas e 187 nãovenenosas. Das 69 espécies venenosas, 32 pertencem ao gênero Bothrops, 6 ao gênero Crotalus, duas ao gênero Lachesis e 29 ao gênero Micrurus.

A grande maioria das serpentes venenosas pertence a quatro ou cinco famílias:

- Elapidae (proteróglifas) - As cobras desta família, responsáveis por uma ínfima parte de acidentes no Brasil, são representadas no Brasil pelas corais-verdadeiras, gênero Micrurus (Borges 1999). Dentro dessa família, que ocorre principalmente na Aus- 
trália, África e Ásia (Habermehl 1977) e não existe na Europa (Borges 1999), estão incluídas ainda as mambas (Dendroapis spp), najas ou "cobras" (Najas spp), taipans (Oxyuranus scutellatus), "kraits" (Bungarus spp), "tiger snake" - cobra-tigre (Notechis scutatus) e a "death adder" - víbora-da-morte (Acantophis antarcticus); esta última, apesar de seu nome e sua aparência, é uma serpente da família Elapidae (Clarke \& Clarke 1969, Humphreys 1988, Mosmann 2001).

- Viperidae (solenóglifas, sem fosseta loreal) - As cobras desta família só existem na Europa, África e Ásia (Soerensen 1990, Clarke \& Clarke 1969) e não ocorrem no Brasil (Borges 1999). São as víboras (adder) verdadeiras (Borges 1999, Humphreys 1988, Habermehl 1977).

- Crotalidae (solenóglifas, com fosseta loreal) - São encontradas nas Américas e na Ásia. A esta família pertencem as serpentes venenosas mais importantes do Brasil, quais sejam as jararacas, urutus e cruzeiras (Bothrops), cascavéis (Crotalus) e a surucucu (Lachesis) (Habermehl 1977). Nos Estados Unidos essa família é representada pelas "rattle snakes" - cobras-de-chocalho (Crotalus) e moccasins (Akistrodon) (Habermehl 1977). Deve-se ressaltar que muitos autores consideram a família Crotalidae apenas como uma subfamília da família Viperidae, denominada Crotalinae.

- Hydrophiidae (proteróglifas, adaptadas à vida marinha) - Esta família não ocorre no Brasil (Borges 1999).

- Pode-se ainda acrescentar a família Colubridae (serpentes áglifas ou opistóglifas, sem fosseta loreal), a que pertencem as falsas-corais. Sua distribuição é cosmopolita. A maioria somente causa dor local e tumefação, mas há duas espécies na África, Dispholidus typus e Thelotornis kirtlandi, que podem produzir envenenamentos sérios, com raros casos fatais (Habermehl 1977, Mosmann 2001).

\section{Habitat}

As serpentes podem ser aquáticas ou terrestres, existindo ainda espécies anfibias. Entre as terrestres há aquelas que vivem sobre árvores (dendrícolas), as que habitam a superfície do solo e as de vida subterrânea. Das que vivem sobre o solo, ganham destaque as dos grupos crotálico, botrópico e laquético. Devese assinalar que as do grupo botrópico podem ser eventualmente encontradas em árvores. Os ofídios peçonhentos são mais encontrados nos campos ou em áreas cultivadas do que no interior de florestas, nas quais há escassez de pequenos roedores, especialmente ratos. De modo geral, pode-se dizer que as serpentes do grupo crotálico preferem locais mais secos e pedregosos, enquanto as do grupo botrópico ocorrem com maior frequiência em áreas mais úmidas, como banhados, beiras de rios e lagoas. Em nosso meio constata-se um fenômeno bastante interessante. Nas matas ou áreas não-devastadas pelo homem, encontram-se aproximadamente $80 \%$ de serpentes não-venenosas e $20 \%$ de venenosas. Nas áreas dedicadas às atividades agropecuárias ocorre uma inversão, devida à presença de roedores, registrando-se nesses locais, $80 \%$ de serpentes venenosas e $20 \%$ de não-venenosas. As cobras do grupo elapídico preferem vida subterrânea. (Belluomini 1976).

\section{Distribuição}

A distribuição dos principais ofídios peçonhentos no Brasil consta na Fig. 1.

\section{Freqüência e susceptibilidade a acidentes ofídicos}

Em humanos, os acidentes botrópicos são mais freqüientes do que os crotálicos; acidentes determinados pela picada de Lachesis muta (surucutinga, surucucu-de-fogo, surucucu-pico-dejaca) e os causados por serpentes do gênero Micrurus (coraisverdadeiras), são bem menos comuns (Borges 1999, Barraviera \& Pereira 1994).

Há considerável variação na susceptibilidade dos diferentes animais aos efeitos dos venenos ofídicos. Nos experimentos realizados por Araujo \& Belluomini (1960/62), eqüinos, ovinos e bovinos mostraram maior sensibilidade ao veneno de ofídios, vindo depois, em ordem decrescente, caprinos, caninos, coelhos, suínos, cobaias, camundongos, gatos e hamsters. Já de acordo com Belluomini et al. (1983), os bovinos reagiriam de maneira mais sensível a venenos de cobras, seguindo-se eqüinos, ovinos, caprinos, caninos e suínos. De acordo com Rosenfeld (1971), carnívoros parecem ser mais resistentes a venenos ofídicos do que outros animais, no entanto o gato é resistente ao veneno botrópico (proteolítico e coagulante) e muito sensível ao veneno de Crotalus spp sul-americanas; já o hamster é mais resistente do que o gato ao veneno crotálico.

\subsection{Ação do Veneno e Quadros Patológicos Observados no Homem e em Animais de Laboratório, Inclusive Cães} Segundo sua ação tóxica principal, os venenos das serpentes podem ser divididos em 3 grupos:

- Veneno crotálico (as espécies de Crotalus sul-americanas), que possui como componente principal uma neurotoxina;

- Veneno botrópico (Bothrops, Vipera, Lachesis e as espécies de Crotalus da América Central e do Norte), que causa necrose local; e

- Veneno elapídico, que causa quase exclusivamente sintomas nervosos (Stöber 2002). Habermehl (1977) chama a atenção para o fato de que, no caso dos acidentes com a sul-americana Crotalus durissus terrificus não ocorrem as lesões locais observadas nos casos de envenenamento por cascavéis norte-americanas.

Em relação à ação e ao quadro clínico-patológico que as toxinas ofídicas provocam, há, no Brasil, muitos estudos, baseados, na sua maioria, em envenenamentos no homem e em experimentos realizados em animais de laboratório e no cão. Apesar de a maioria desses estudos valerem, em parte, para o bovino, é necessário alertar que os sintomas e as lesões, além de variarem com o gênero e a espécie da serpente, também diferem em função da espécie dos animais-vítima (Amorim et al. 1951).

Os dados a seguir referem-se à ação dos venenos e têm como base os textos de Amaral \& Rezende (1994), Azevedo-Marques et al. (2003), Barraviera (1994, 1999), Barraviera \& Pereira (1994), Borges (1999), França \& Málaque (2003) e Málaque \& França (2003).

\section{Crotalus spp}

Ação neurotóxica. As frações neurotóxicas (fundamentalmente a crotoxina) do veneno crotálico produziriam efeitos tanto no sistema nervoso central, quanto no sistema nervoso periférico. A crotoxina induz à paralisia, semelhante à causada pelo curare, em todas as espécies animais estudadas. Sugere-se que as paralisias motora e respiratória no envenenamento crotálico 

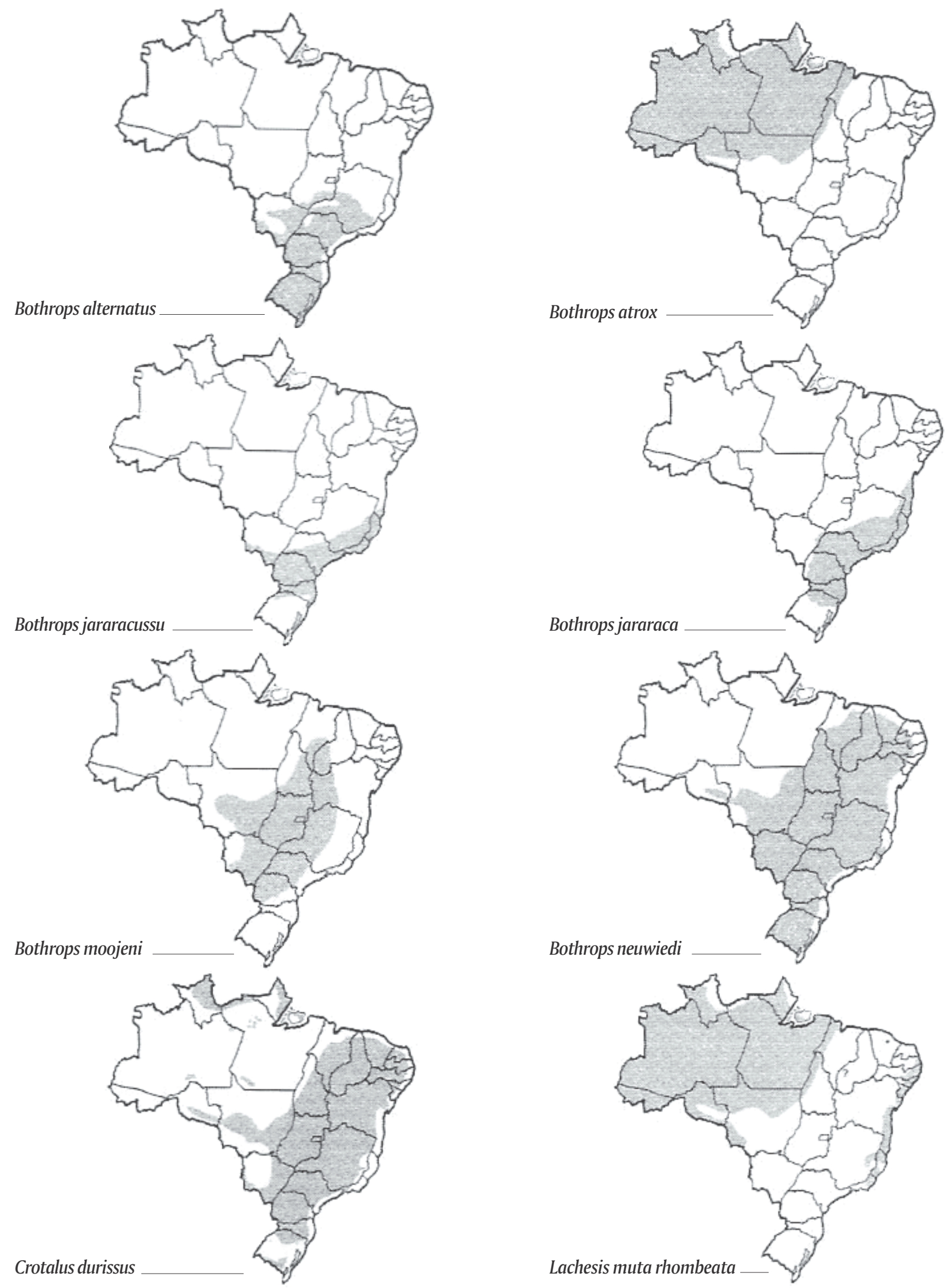

Fig.1. Distribuição dos principais ofídios peçonhentos no Brasil (Melgarejo 2003). 
sejam decorrentes do bloqueio da transmissão nervosa na junção neuromuscular, por ação da neurotoxina que inibe a liberação de acetilcolina na sinapse.

Ação miotóxica. Tem sido atribuída à crotoxina, e mesmo à crotamina, a capacidade de produzir lesões no tecido muscular esquelético, sistemicamente, em pontos distantes do local da picada; há rabdomiólise sistêmica, traduzida por necrose hialina das fibras musculares esqueléticas, com conseqüiente mioglobinúria.

Ação coagulante. A ação coagulante, semelhante à da trombina, acaba determinando um consumo dos fatores da coagulação e, por fim, a "incoagulabilidade" sanguínea. Há queda dos níveis sanguiíneos de fibrinogênio com prolongamento do tempo de coagulação, ausência de protrombina e deficiência parcial de tromboplastina, sem redução do número de plaquetas. Apesar das alterações nos testes de coagulação, as manifestações hemorrágicas são discretas.

Ação nefrotóxica. O veneno crotálico ocasionaria lesão tubular direta, mas admite-se ainda uma ação indireta pela mioglobinúria (obstrução tubular por cilindros de mioglobina e lesão dos túbulos pelo miopigmento). Outros fatores, correlatos ao choque (desidratação com elevação do hematócrito, hipotensão arterial, acidose metabólica e sequiestro de líquidos para a musculatura esquelética), podem estar associados à rabdomiólise e contribuem para a instalação da lesão renal. Nos casos que evoluem para a insuficiência renal aguda (IRA), há oligúria e anúria.

Quadro patológico do envenenamento crotálico. A lesão renal é referida como necrose tubular aguda, mas também têm sido relatadas glomerulonefrite e nefrite intersticial agudas, degeneração hidrópica e presença de cilindros de mioglobina. Nos músculos encontra-se necrose hialina das fibras musculares esqueléticas. No fígado haveria degeneração hidrópica dos hepatócitos com localização centrolobular. As hemorragias seriam raras nos órgãos internos, porém ocorreriam com maior frequiência no sistema nervoso central. As causas mais importantes da morte são a IRA (a insuficiência respiratória aguda) e o choque (este último é menos freqüente no acidente crotálico do que nos acidentes botrópico e laquético).

\section{Bothrops spp}

Ação necrosante ou proteolítica. Decorre da ação citotóxica direta de frações proteolíticas do veneno. A esta ação atribuemse, principalmente, as lesões locais como rubor, edema, vesículas e necrose; os efeitos vasculo-tóxico e coagulante também podem contribuir para a instalação dessas lesões.

Ação vasculo-tóxica (hemorrágica). Determina aumento de permeabilidade ou rompimento da membrana basal do endotélio vascular e conseqüentes edema e hemorragia. As hemorragias podem ser locais ou sistêmicas, afetando os pulmões e rins; às vezes são fatais, quando no sistema nervoso central. Além do edema no local da picada, há hemorragias na gengiva, epistaxe, hematemese, hematúria, hemorragia digestiva alta, e, às vezes, até no bordo do leito ungueal.

Ação coagulante. Além de ativar o fibrinogênio, a fração coagulante da maioria dos venenos botrópicos tem capacidade de ativar o fator X e a protrombina. Quando ocorre a ativação do fator X, há também consumo dos fatores V, VII e de plaquetas, levando ao quadro de coagulação intravascular disseminada (CID), com formação de microtrombos na rede capilar, o que poderia contribuir para desencadear a insuficiência renal aguda (IRA).

Outras ações. Os acidentes botrópicos podem ser acompanhados de choque, com ou sem causas definidas, entre elas, a hipovolemia por perda de sangue ou plasma no membro edemaciado, a ativação de substâncias hipotensoras, o edema pulmonar e a coagulação intravascular disseminada. A insuficiência renal, observada eventualmente em envenenamentos botrópicos, poderia instalar-se por ação direta ou secundária a complicações em que o choque está presente; além disto, se admite que a CID é capaz de provocar isquemia renal por obstrução da microcirculação Outro mecanismo proposto para explicar as lesões é ainda espasmo dos vasos renais por liberação de substâncias vasoativas.

Quadro patológico no envenenamento botrópico. Amorim et al. (1951) descreveram, no local da injeção, forte hemorragia e edema com necrose de coagulação do tecido subcutâneo e dos músculos estriados subjacentes, hemorragias em vários órgãos internos e trombose hialina nos capilares em $60 \%$ dos casos, principalmente no pulmão (em $47 \%$ dos casos). Os autores chamam a atenção para o valor que poderia ter esta última lesão para o diagnóstico do envenenamento ofídico. No rim esses autores encontraram somente lesões hiperêmico-hemorrágicas. Por outro lado, outros descrevem necrose tubular aguda, necrose cortical renal e, ocasionalmente, glomerulonefrite e nefrite intersticial. As causas da morte, em geral, são insuficiência renal aguda (IRA) e hemorragias incontroláveis, além do choque.

\section{0 veneno de Lachesis muta}

Possui ações proteolítica (necrosante), coagulante e vasculotóxica; admite-se ainda uma ação neurotóxica. As serpentes do gênero Micrurus produzem veneno que têm, principalmente, ação neurotóxica.

\subsection{Dados Sobre a Importância de Acidentes Ofídicos como Causa de Mortes em Bovinos}

De acordo com Pacheco \& Carneiro (1932), o homem do campo tem uma tendência inata a atribuir às plantas e às cobras a maioria das "mortes súbitas" em bovinos. Esses autores acreditavam "que nem as plantas tóxicas, nem as cobras têm esta importância como causa de mortes" e eram da opinião que as principais causas das "mortes súbitas" em bovinos seriam o carbúnculo hemático e o carbúnculo sintomático.

Araújo et al. (1963) deixam em aberto a questão da importância dos acidentes ofídicos em bovinos ao afirmarem que, no campo da veterinária, a questão dos envenenamentos ofídicos em bovinos ainda estaria muito obscura.

Grunert \& Grunert (1969) tecem considerações sobre a imunização contra o envenenamento ofídico de animais de alto valor e concluem que a imunidade não chegaria a ter importância prática, porque é de curta duração, a vacinação é cara e o perigo de picadas de cobra seria relativamente baixo para bovinos e eqüinos. Especificamente em relação aos acidentes por cobras do gênero Bothrops, Grunert (1967) e Grunert \& Grunert (1969) comentam que casos fatais em bovinos são raros dada à 
toxicidade relativamente baixa dos venenos dessas cobras para grandes animais domésticos.

Belluomini et al. (1983) também deixam a questão da significância dos acidentes ofídicos em bovinos em aberto ao dizerem que "não há dados sobre o número de mortes de bovinos, que foram vitimados por cobras venenosas, conseqüentemente não há cálculos econômicos sobre estas perdas; os fazendeiros avaliam como importantes os casos de mortes em bovinos causadas por cobras, em especial as causadas por picada de cascavel".

Novaes et al. (1986) afirmam que "os animais domésticos constantemente são vítimas de animais peçonhentos e os pecuaristas voltam sua atenção para estes acidentes, principalmente em bovinos, devido aos prejuízos decorrentes e também pela dificuldade de tratamento".

Mais tarde, Belluomini (1990) afirma, em contradição ao seu trabalho anterior, que "a freqüência de acidentes ofídicos nos animais domésticos é imprecisa, apesar da grande significância econômica, e que embora não exista estimativa de acidentes e respectiva mortalidade de bovinos por acidentes ofídicos, provavelmente em número bastante elevado, muitos criadores de gado confirmam (grifo nosso) grande perda de bovinos atribuída à picada de Crotalus ou de Bothrops".

Bicudo (1994) concorda que as estatísticas sobre acidentes ofídicos são bastante escassas na literatura veterinária e informa que os primeiros registros sobre esse tipo de envenenamento foram feitos por intermédio de boletins de notificações, que acompanhavam as ampolas de soro antiofídico, distribuídos pelo Instituto Butantan. Entre outros, cita Fonseca (1949) que, ao compilar os dados dos boletins desse Instituto em um período de 43 anos, encontrou 1.658 notificações de acidentes em animais com 151 mortes. Infelizmente não são mencionadas as espécies animais a que se referem esses números.

Em estudo retrospectivo realizado a partir de prontuários de animais atendidos entre 1972 e 1989 no Hospital Veterinário da Faculdade de Medicina Veterinária e Zootecnia (FMVZ) da Unesp-Botucatu, Bicudo \& Biondo (1989) encontraram 149 registros de acidentes ofídicos, dos quais 128 referem-se a acidentes por serpentes do gênero Bothrops, 11 por Crotalus e a 10 acidentes ofídicos sem identificação. Desses acidentes, 103 ocorreram em caninos, 22 em eqüinos, 17 em bovinos, 4 em caprinos, 2 em gatos e um em suíno. Infelizmente não são fornecidos dados sobre letalidade em cada espécie animal, quais foram as serpentes envolvidas em relação a cada espécie animal, nem há informações sobre os quadros clínico-patológicos ou como foram feitos esses diagnósticos.

Bicudo (1994) ainda menciona os dados de Stefanini (1991) referentes à mortalidade de bovinos, que teria ocorrido entre 1973 e 1991, em sete fazendas localizadas em cinco municípios do Estado de São Paulo. Nesse período teriam morrido 358 animais por acidentes ofídicos; considerando a população total dos bovinos dessas fazendas, a mortalidade anual por esse tipo de acidente oscilaria entre 0,13 e 1,2\%. Também não há indicações de como foram estabelecidos os diagnósticos, nem sobre alterações clinico-patológicas. Bicudo (1994) acrescenta: “estimando a população bovina em torno de 100 milhões de cabeças, e aplicando o índice de $0,13 \%$, o número de animais mortos por envenenamento ofídico no Brasil seria de 130 mil cabeças por ano".

Menezes (1995/96) informa que os ataques ofídicos são de baixa incidência nos atendimentos ambulatoriais na Clínica de Bovinos da Escola de Medicina Veterinária da Universidade Federal da Bahia.

De acordo com Méndez (2001), no Rio Grande do Sul ocorrem casos esporádicos de acidentes ofídicos em bovinos e eqüinos, geralmente devidos a serpentes do gênero Bothrops; raramente esses animais são levados aos laboratórios para se estabelecer a causa da morte e, em consequiência, há poucos dados sobre o quadro clínico-patológico provocado pelo veneno.

De acordo com a Fundação Ezequiel Dias (Governo de Minas Gerais), picadas de cobra seriam responsáveis por cerca de 75.000 mortes de bovinos a cada ano no Brasil, embora não seja fornecida a base para essa afirmação. (Anônimo 2004).

\subsection{Descrições do Quadro Clínico-Patológico de Acidentes Ofídicos em Bovinos no Brasil \\ Acidente crotálico}

Não há relatos de casos naturais de acidentes por Crotalus em bovinos no Brasil. Quase tudo que se sabe sobre a ação do veneno de serpentes desse gênero e sobre o correspondente quadro clínico-patológico do envenenamento crotálico em bovinos, se baseia na experimentação.

Envenenamento natural. Bicudo (1994) afirma que a casuística sobre acidentes crotálicos em bovinos é bastante escassa, e sem fornecer outros detalhes, observa que, em casos naturais desse tipo de envenenamento em bovinos, a dificuldade visual, que seria o sintoma mais evidente, se deve à paralisia motora, reversível, do globo ocular. A constatação dessa paralisia é feita por meio de rotação da cabeça do animal nos sentidos horário ou anti-horário. Em condições normais, o sentido do movimento do globo ocular é contrário ao sentido da rotação da cabeça, aparecendo nitidamente a esclerótica. Nos animais envenenados, os globos oculares acompanham o movimento no sentido da rotação, não sendo possível expor a esclerótica. Em bovinos que sobrevivem ao acidente, essa alteração desaparece em algumas semanas.

Envenenamento experimental. Araujo et al. (1963) não verificaram necrose no local da aplicação do veneno crotálico (intramuscular no bordo posterior da coxa e subcutâneo na bochecha) em 13 bovinos, nem fornecem outros dados sobre 0 quadro clínico-patológico observado nesses experimentos.

Em 92 bovinos que receberam, por via intramuscular, uma mistura de venenos de Crotalus durissus terrificus e Crotalus durissus collilineatus, e depois foram tratados com soro antiofídico específico, Belluomini et al. (1982) observaram, 2-6 horas após a aplicação do veneno, dificuldades de locomoção e de ficar em estação, permanência em decúbito lateral, abolição do reflexo palpebral, porém sem ptose, abolição do reflexo pupilar fotomotor, paralisia motora reversível do globo ocular entre 6 e 72 horas, ausência de hemoglobina e de outras alterações macroscópicas da urina ou da micção; verificaram ainda sintomas interpretados como secundários, entre eles apatia, sialorréia, anorexia, sede, paresia do rúmen e timpanismo agudo. 
Pelas análises da urina de 15 bovinos que, ao que tudo indica, receberam o mesmo veneno acima citado (dos quais 10 foram tratados com soro antiofídico específico e 5 não receberam tratamento; morreram os 5 animais não-tratados e mais 7 dos tratados, num prazo de 7-156 horas após a aplicação do veneno), Birgel et al. (1983) concluíram que esse veneno causa lesão progressiva do néfron com diminuição de capacidade de reabsorção de substâncias à altura dos túbulos contornados proximais, seguida de proteinúria, glicosúria e concentração urinária diminuída (sic). Em 60\% dos casos havia microhematúria, congestão renal e maior permeabilidade dos glomérulos renais. Esses achados indicariam uma glomerulonefrite. Apesar da administração de doses letais, não se conseguiu demonstrar efeito hemolítico e conseqüente hemoglobinúria. Os autores ainda afirmam que, através do exame de urina, em bovinos seria fácil diferenciar o envenenamento crotálico (sem hematúria e sem hemorragias) do produzido por jararacas (hematúria e hemorragias extensas) e intoxicação por plantas que causam hemoglo-binúria.

Através de estudos anátomo-histopatológicos realizados em 16 bovinos (que, ao que tudo indica, fizeram parte do estudo de Belluomini et al.1982), aos quais fora aplicado o mesmo veneno crotálico (todos os 12 tratados com soro específico, bem como os quatro não-tratados, morreram), Saliba et al. (1983) relataram as seguintes lesões macroscópicas: petéquias em todos os órgãos e congestão em serosas e mucosas, mais presentes no sistema nervoso central, onde, ocasionalmente, também foram observadas extensas hemorragias subdurais. No local da injeção do veneno mencionam uma inflamação seroso-purulenta (sic) da pele e do tecido subcutâneo, que clinicamente não foi possível reconhecer. Ao exame microscópico, observaram numerosas hemorragias subdurais e acúmulo de sangue nos espaços perivasculares no sistema nervoso central. Em $43 \%$ dos bovinos descreveram necrose hialina nas paredes das arteríolas no sistema nervoso central, no pulmão e no local da aplicação do veneno, e trombos hialinos na luz de arteríolas e capilares pulmonares, em 31\% dos casos. No rim havia processos degenerativos, inclusive degeneração hidrópica culminando em necrose tubular e presença de albumina no espaço intracapsular (sic). Na luz dos túbulos não se observaram cilindros hialinos ou de hemoglobina, porém, em $31 \%$ dos animais, havia glomerulonefrite focal. No miocárdio havia degeneração vacuolar.

Através da inoculação intramuscular do veneno de Crotalus durissus terrificus em cinco bovinos com 2-3 anos, Lago (1996) observou severo quadro neurológico, caracterizado cronologicamente por apatia, letargia profunda, mioclonias, diminuição do tônus muscular, diminuição de reflexos superficiais, incoordenação motora, decúbito lateral, movimentos de pedalagem, perda de sensibilidade à dor profunda, paralisia flácida, dispnéia e morte de $20 \mathrm{~h} 42 \mathrm{~min}$ a $39 \mathrm{~h} 24 \mathrm{~min}$ após a inoculação. Pequeno edema transitório foi observado no local da inoculação. Houve aumento do tempo de coagulação sangüínea, leucocitose, hipofibrinogenemia e aumento da concentração sérica de uréia e de creatinafosfoquinase. As alterações anátomo-histológicas consistiram em leves hemorragias nos pulmões, intestinos, músculos, e em maior intensidade, no coração. Nos músculos esqueléticos e cardíaco havia degeneração hialina, vacúolos e infiltrados celulares.

\section{Acidente botrópico}

Há poucos estudos de casos naturais de acidentes letais por Bothrops em bovinos. Foram feitos muitos experimentos com o veneno de serpentes do gênero Bothrops nessa espécie, porém sem descrição detalhada do quadro clínico-patológico (Araújo \& Belluomini 1960-62, Araujo et al. 1963, Belluomini et al. 1983). Só Novaes et al. (1986) fornecem alguns dados sobre o quadro clínico-necroscópico de bovinos (sem descrição das alterações histológicas) envenenados experimentalmente através de picada ou injeção do veneno de diversas espécies de Bothrops, enquanto Oliveira et al. (2004a,b) relatam os achados histopatológicos em 2 bovinos e as alterações sanguíneas em 5 vacas envenenados através da inoculação do veneno de $B$. alternatus.

Envenenamento natural. Grunert (1967) e Grunert \& Grunert (1969) informam que, no período de 1964-1966, deram entrada no Hospital de Clínica Veterinária da Universidade do Rio Grande do Sul, em Porto Alegre, quatro vacas com lesões características de envenenamento botrópico. O principal sintoma observado por esses autores foi um considerável aumento de volume, de consistência macia, no local da picada. Se a picada era na cabeça, havia dispnéia e inquietação, se nos membros, verificava-se andar claudicante. Em casos graves havia hemorragias pela boca e pelas narinas, as fezes eram aquosas e hemorrágicas e as mucosas anêmicas. Até o $3^{\circ}$ dia, a tumefação aumentava pouco a pouco; depois começava a diminuir devagar, a partir do $5^{\circ}$ dia, apesar de tratamento sintomático. Devido às alterações necróticas no local da picada, a partir do $2^{\circ}$ e $3^{\circ}$ dias, havia cheiro pútrido. Na maioria dos casos, o estado geral estava bem alterado; os animais tinham andar cambaleante, inapetência, e estavam apáticos, inapetentes e gemiam. Observaram-se aumento das frequiências cardíaca e respiratória, as conjuntivas e as mucosas estavam congestas. Os animais não se alimentavam normalmente antes de 2-3 semanas. Só uma vaca recebeu, por via endovenosa, soro antiofídico, 6 horas após o acidente, porém teve o mesmo quadro clínico que os outros animais, que não receberam soro anti-ofidico. Apenas uma dessas vacas, gravemente afetada, morreu, com hemorragias pelas narinas, boca e reto, 12 horas após a entrada, apesar de tratamento intensivo. A necropsia desta vaca revelou, além de edema e hemorragias do tecido subcutâneo no local da picada, graves hemorragias nas cavidades corporais e no trato digestivo. No coração e nas mucosas da cavidade bucal, do estômago (sic), do intestino e dos órgãos urinários e sexuais havia alterações hiperêmico-hemorrágicas. Não há descrição das alterações histológicas.

De acordo com Menezes (1995/96), em 7 casos naturais de envenenamento botrópico, diagnosticados na Clínica de Bovinos da Escola de Medicina Veterinária, Universidade Federal da Bahia, nos anos de 1985-1995, a sintomatologia caracterizavase por apatia, súbito edema no local, dor, aumento de volume dos linfonodos regionais, hipertermia, anorexia, taquicardia, polipnéia e dispnéia mista, claudicação, além de necrose no local da picada, diminuição da coagulabilidade sangüínea e aborto. Os achados de necropsia verificados no único bovino que morreu (bezerra com idade de $1 \mathrm{dia}$ ) foram acentuado edema e grande área de necrose no local da ferida (região perineal e vulva), da qual fluía líquido sero-sangüinolento, hemorragias retal e vagi- 
nal, petéquias nos linfonodos superficiais, no epicárdio, na mucosa intestinal e da bexiga, congestão dos pulmões e incoagulação do sangue (sic). Não são fornecidas descrições das alterações histológicas.

Envenenamento experimental. Ao inocular em 35 bovinos o veneno das principais cobras do gênero Bothrops, pelas vias intramuscular (bordo posterior da coxa) e subcutânea (bochecha), para averiguar quais as serpentes que eventualmente poderiam produzir acidentes fatais nessa espécie, Araújo et al. (1963) constataram que os venenos botrópicos, independentemente da via de inoculação, das doses usadas e do local da inoculação, produziram acentuado edema em todos os bovinos. A necrose foi observada apenas através da inoculação por via intramuscular, com exceção do veneno de $B$. cotiara, que não produziu necrose em nenhum animal. Por via subcutânea, os venenos botrópicos não produziram necrose, provavelmente devido à sua difusão por extensa área.

Novaes et al. (1986), com base em 42 experimentos realizados em bovinos para verificar o comportamento de um anti-inflamatório no tratamento do edema produzido no envenenamento por diversas espécies de Bothrops, descrevem o aspecto das lesões no local da picada (na face) ou da injeção de veneno (na bochecha, via subcutânea). Os autores relatam que, tanto nos bovinos tratados como nos testemunhas, se formou, momentos depois da picada ou da inoculação do veneno, um edema que se difundia pela face, queixo, barbela, até o peito. Este edema atingia o grau máximo, em média, às 48 horas pós-inoculação, podendo perdurar por 120 horas ou mais. Em todos os casos, o edema produzido por picada foi menor que o produzido por inoculação. Os edemas mais intensos foram provocados pelas espécies B. jararacussu, B. alternatus, B. atrox e B. moojeni, e os menos intensos por $B$. jararaca e $B$. neuwiedi. Os autores observaram que os traumatismos sofridos pelos animais no tronco de contenção deram origem a grandes hematomas. À necropsia verificou-se extenso edema sero-hemorrágico subcutâneo, que se estendia do local da inoculação na face, ao queixo, barbela e parte do tórax. À abertura da cavidade abdominal havia petéquias e sufusões subserosas no intestino grosso e rúmen. Hemorragias intestinais foram encontradas apenas em um animal, que apresentou as mucosas anêmicas. Na cavidade torácica, as lesões se limitavam a petéquias no coração e pericárdio (sic) e, por vezes, a presença de líquido sero-hemorrágico na cavidade pericárdica. Não foram fornecidos dados sobre alterações histológicas. Nos animais que morreram, inoculados ou por picada, a evolução oscilou entre 24 e 72 horas.

Em dois bovinos inoculados (via não-especificada), Oliveira et al. (2004a) descreveram necrose intensa e difusa, associada a infiltrado inflamatório neutrofilico na musculatura do membro anterior inoculado, nos linfonodos cervicais superficiais, do lado do músculo do membro que sofreu a inoculação, hiperplasia reacional dos folículos linfóides, parede da vesícula biliar intensamente hemorrágica e edematosa, com proliferação linfóide na submucosa, baço com acentuada congestão e hiperplasia de folículos linfóides; em um bovino havia ainda infiltrado inflamatório neutrofílico, associado a hemorragia intensa e fibrina no epicárdio, e no miocárdio, congestão, hemorragia e infiltrado neutrofílico perivascular.
Em cinco vacas inoculadas (via não-especificada) com o mesmo veneno, Oliveira et al. (2004b) constataram alterações do perfil sangüíneo caracterizadas por leucocitose, anemia normocítica normocrômica e redução de TP (proteínas totais).

\section{Veneno crotálico}

\subsection{Doses Tóxicas}

Pela inoculação de veneno crotálico nas doses de 0,025 $0,190 \mathrm{mg} / \mathrm{kg}$ (miligramas de veneno por $\mathrm{kg}$ de peso do animal), Araújo et al. (1963) (ver 1.4., p.60) verificaram que, pelas vias intramuscular e subcutânea, a dose letal mínima foi $0,05 \mathrm{mg} / \mathrm{kg}$ (em ambos os casos, morte em menos de um dia após a inoculação). Os autores ponderam que, considerando-se a quantidade total de veneno que $75 \%$ das serpentes fornecem na primeira extração, hipoteticamente correriam risco de vida bovinos de até $2.000 \mathrm{~kg}$, (refazendo os cálculos desses autores, encontramos que bovinos de até $1.000 \mathrm{~kg}$ poderiam morrer, caso fossem picados por essas serpentes, o que na prática faz pouca diferença). (Quadro 1)

Através da inoculação intramuscular de uma mistura de venenos de Crotalus durissus terrificus e Crotalus durissus collilineatus na dose de $0.05 \mathrm{mg} / \mathrm{kg}$, em 92 bovinos (ver 1.4., p.60), Belluomini et al. (1982) fizeram as seguintes observações: 1) os bovinos são muito sensíveis à fração neurotóxica do veneno crotálico e menos à fração hemolítica (sic); 2) a letalidade é alta mesmo nos animais tratados dentro de até 6 horas com soro específico, apesar de a dose do soro ter sido, em teoria, suficiente para neutralizar uma quantidade de veneno uma a 4 vezes superior à inoculada; 3) a morte ocorre freqüentemente dentro das primeiras 24 horas; apenas 15 animais (16,3\%), morreram em até 4 dias depois da aplicação do veneno.

No estudo experimental de Saliba et al. (1983) (ver 1.4., p.60), o veneno crotálico, aplicado por via subcutânea na dose $0,05 \mathrm{mg} /$ $\mathrm{kg}$, determinou a morte de todos os 16 bovinos, tratados e nãotratados.

Já no estudo experimental de Lago (1996), a inoculação intramuscular de $0,03 \mathrm{mg} / \mathrm{kg}$ do veneno de Crotalus durissus terrificus, causou a morte de todos os cinco bovinos (ver 1.4., p.60).

\section{Veneno botrópico}

Um resumo do trabalho de Araujo et al. (1963), previamente mencionado (ver 1.4., p.62), encontra-se no Quadro 1, elaborado por Belluomini (1976), e é aqui parcialmente reproduzido, com acréscimos nossos. Na coluna A deste quadro consta a quantidade de veneno em miligramas, que $75 \%$ das serpentes fornecem na primeira extração. Na coluna B encontram-se as doses letais dos diferentes venenos quando injetados na coxa ou na bochecha de bovinos, possibilitando, ainda, a comparação das quantidades secretadas pelas serpentes com a quantidade de veneno necessária para matar um bovino de $400 \mathrm{~kg}$. Na coluna C menciona-se (em $\mathrm{kg}$ ) o peso (hipotético) de um bovino que poderia ser morto em acidente ofídico, considerando-se a média da quantidade total de veneno que $75 \%$ das cobras dessa espécie fornecem na primeira extração. Na coluna D destaca-se que peso hipotético (em kg) teria um bovino passível de ser morto se todo o veneno lhe fosse inoculado., porém considerando-se o máximo de veneno encontrado no exemplar dessa espécie que mais produziu veneno. 
Quadro 1. Relação entre a quantidade de veneno secretada e possibilidade de envenenamento fatal por algumas serpentes brasileiras ${ }^{\mathrm{a}}$

\begin{tabular}{|c|c|c|c|c|c|c|c|c|}
\hline \multicolumn{3}{|c|}{ A } & \multicolumn{4}{|c|}{ B } & $\mathrm{C}$ & D \\
\hline \multirow[t]{2}{*}{ Serpente } & \multirow{2}{*}{$\begin{array}{l}\text { Média da } \\
\text { quantidade } \\
\text { total de } \\
\text { veneno }(\mathrm{mg}) \\
\text { fornecido } \\
\text { por } 75 \% \text { das } \\
\text { serpentes na } \\
\text { primeira } \\
\text { extração }\end{array}$} & \multirow{2}{*}{$\begin{array}{l}\text { Máximo } \\
\text { extraído } \\
(\mathrm{mg}) \text { do } \\
\text { ofídio que } \\
\text { mais } \\
\text { produziu } \\
\text { veneno }\end{array}$} & \multicolumn{4}{|c|}{$\begin{array}{l}\text { Dose letal de veneno para bovinos } \\
\text { Coxa (intramuscular) }\end{array}$} & \multirow{2}{*}{$\begin{array}{c}\text { Peso } \\
\text { hipotético } \\
(\mathrm{em} \mathrm{kg)} \\
(75 \%)^{\mathrm{b}}\end{array}$} & \multirow{2}{*}{$\begin{array}{c}\text { Peso } \\
\text { hipotético } \\
\text { máximo } \\
(\mathrm{em} \mathrm{kg)c}\end{array}$} \\
\hline & & & $\begin{array}{l}\mathrm{mg} / \mathrm{kg} \\
\text { dose letal }\end{array}$ & $\begin{array}{c}\text { Para bovino } \\
\text { de } 400 \mathrm{~kg} \\
(\mathrm{mg})\end{array}$ & $\begin{array}{c}\text { Bochecha } \\
\text { (subcutâneo) } \\
\mathrm{mg} / \mathrm{kg} \\
\text { dose letal }\end{array}$ & $\begin{array}{c}\text { Para } \\
\text { bovino } \\
\text { de } 400 \\
\text { kg (mg) }\end{array}$ & & \\
\hline \multicolumn{9}{|c|}{ Bothrops } \\
\hline B. jararacussu & 400 & 830 & 2,00 & 800 & 1,60 & 640 & $250(\mathrm{sc})$ & 581 \\
\hline B. alternatus & 130 & 380 & 0,45 & 180 & 0,25 & 100 & $520(\mathrm{sc})$ & 950 \\
\hline B. moojeni & 105 & 300 & 2,00 & 800 & 0,41 & 164 & 255 (sc) & 731 \\
\hline B. jararaca & 65 & 160 & 1,00 & 400 & 1,00 & 400 & 65 & 160 \\
\hline B. cotiara & 65 & 120 & 0,25 & 100 & 0,25 & 100 & 260 & 480 \\
\hline B. neuwiedi & 45 & 100 & 1,00 & 400 & 1,00 & 400 & 45 & 100 \\
\hline \multicolumn{9}{|c|}{ Crotalus } \\
\hline C. durissus ter & ificus 50 & 220 & 0,05 & 20 & 0,05 & 20 & 1000 & 4400 \\
\hline \multirow{2}{*}{\multicolumn{9}{|c|}{$\begin{array}{l}\text { Realizada a extração, o veneno das cobras, depois de seco, fica reduzido a } 25 \text { \% de seu volume original. Todos os dados } \\
\text { indicados nesse trabalho se referem ao veneno seco } \\
\text { Peso hipotético (em kg) de um bovino passível de ser morto em acidente ofídico considerando-se a quantidade de } \\
\text { veneno que } 75 \% \text { das cobras dessa espécie fornecem na primeira extração. }\end{array}$}} \\
\hline & & & & & & & & \\
\hline \multicolumn{9}{|c|}{$\begin{array}{l}\text { c Peso hipotético máximo (em } \mathrm{kg} \text { ) de um bovino que poderia ser morto em acidente ofídico considerando-se o máximo } \\
\text { de veneno produzido pelo exemplar dessa espécie que mais produziu veneno. }\end{array}$} \\
\hline
\end{tabular}

Com base na média desses experimentos verifica-se que, além de Crotalus spp, somente Bothrops alternatus poderia inocular quantidade suficiente de veneno para matar um bovino de 400 $\mathrm{kg}$. Araujo et al. (1963) também incluem B. cotiara, entre as serpentes potencialmente letais para bovinos de $400 \mathrm{~kg}$, o que provavelmente trata-se de um equívoco, uma vez que, pelo Quadro 1 , pode-se verificar que essa cobra, ao inocular os $65 \mathrm{mg}$ de veneno, só causaria a morte de um bovino de $260 \mathrm{~kg}$. Aliás, todos os valores indicados por Araujo et al. (1963) referentes ao peso dos bovinos que correm risco de vida pelas picadas das diversas cobras, divergem do cálculo de Belluomini (1976), que nos parece mais correto. Mas se fizermos os cálculos pelo máximo de veneno secretado pela cobra que mais produziu veneno dentro de cada uma das diversas espécies de cobra, todas as serpentes do gênero Bothrops, com exceção de $B$. jararaca e $B$. neuwiedi, poderiam matar um bovino com $400 \mathrm{~kg}$.

Já nos experimentos de Novaes et al. (1986) (ver 1.4., p.62.), dos 18 bovinos submetidos a picada de diversas serpentes do gênero Bothrops, isto é, de B. alternatus, B. neuwiedi, $B$. moojeni, $B$. jararacussu, B. jararaca e $B$. atrox apenas um, picado por $B$. alternatus, morreu. Pela inoculação dos venenos de cobras das mesmas espécies, morreram animais que receberam doses menores que as administradas por Araújo et al.(1963), isto é, de $B$. alternatus, B. neuwiedi, B. jararaca e B. atrox. Novaes (2005), consultado sobre essa discrepância, esclareceu que os bovinos usados não eram de primeira linha, praticamente "refugos" do rebanho do Centro de Pesquisa Agropecuária do Pantanal da Embrapa, Corumbá; consultado, ainda, sobre porque morreram mais animais inoculados tratados do que inoculados não-tratados, explicou que isto também se deve ao fato tratar se de "refu- gos". Desta maneira, as doses letais verificadas por Novaes et al. (1986) só poderiam ter validade para animais enfermos ou em má condição física.

Oliveira et al. $(2004 \mathrm{a}, \mathrm{b})$ causaram a morte de dois bovinos com peso médio de $250 \mathrm{~kg}, 53$ e 78 horas após a inoculação de $0,15 \mathrm{mg} / \mathrm{kg}$, num total de $27,5 \mathrm{mg}$ (deve ser $37,5 \mathrm{mg}$ ) do veneno B. alternatus, diluído em solução salina, pela via intramuscular superficial, na face cranial do membro anterior direito. De cinco vacas, inoculadas com $0,15 \mathrm{mg} / \mathrm{kg}$ de veneno de B. alternatus, por via não-indicada, duas morreram em 48 horas. Essas doses letais verificadas por Oliveira et al. (2004a,b), também são mais baixas do que as indicadas por Araújo et al. (1963); os autores não fazem comentários sobre a razão desta divergência. (ver 1.4., p.62)

\subsection{Percentagem de Veneno Inoculado}

Um aspecto fundamental na determinação de até que ponto um acidente ofídico pode ser fatal diz respeito à quantidade de veneno que as serpentes realmente inoculam. Com relação a esse ponto deve-se levar em consideração que 1) as quantidades de veneno que se obtém através das extrações, média e máxima, somente representam o limite superior do volume de veneno que a cobra poderia injetar (Clarke \& Clarke 1969). Allon \& Kochva (1976) dosaram as quantidades de veneno inoculadas por Vipera palaestinae, através de marcadores radioativos; essas quantidades corresponderiam em média a 8\% da quantidade de veneno produzida e armazenada; 2 ) Quando pica, mesmo sendo venenosa, a cobra pode não injetar veneno algum. A expulsão de veneno da glândula é uma ação voluntária, inteiramente sob controle do ofídio, e não é 
simplesmente uma questão da quantidade disponível. Por parte da cobra há um instinto de conservar o veneno, porque é através dele que pode obter o alimento. Uma picada em um grande animal é somente uma reação de defesa - uma cascavel provavelmente não considera um cavalo ou o homem como um alimento em potencial (Clarke \& Clarke 1969). Estes autores afirmam, "que a quantidade de veneno injetado pelas cobras, é completamente variável e imprevisível”. Realmente, sabe-se que em parte dos botes, as serpentes do gênero Crotalus não inoculam veneno. Por exemplo, Melgarejo (2005) verificou, experimentalmente, que, em 10\% dos casos, essas serpentes não inoculam veneno ("picada seca") em camundongos. Mesmo em pacientes humanos está comprovado que, muitas vezes, o ofídio não inocula veneno quando pica; $12 \%$ (Rezende et al. 1998) a $42 \%$ (Silveira \& Nishioka 1995) das picadas de Crotalus são "secas". De acordo com esses últimos autores, em 30\% dos botes, as jararacas também não injetam veneno algum. Ainda deve ser levado em conta que diferentes amostras do veneno de serpentes da mesma espécie podem ter diferentes graus de toxidez em função de variações geográficas ou sazonais, idade, condições de saúde, captividade, coletas de veneno, entre outras (Christensen 1968).

\subsection{NOSSAS OBSERVAÇÕES}

\subsection{Levantamento da Situação junto a Patologistas e Clínicos no Brasil}

Em consulta aos patologistas, Professores Severo Sales de Barros e Cláudio S.L. Barros da Universidade Federal de Santa Maria, RS, Franklin Riet-Correa da Universidade Federal de Campina Grande, Patos, PB, David Driemeier da Universidade Federal do Rio Grande do Sul, Porto Alegre, RS, Aldo Gava da Universidade do Estado de Santa Catarina, Lages, SC, Ricardo Lemos da Universidade Federal de Mato Grosso do Sul, Campo Grande, MS, Carlos Eduardo Pereira dos Santos da Universidade Federal de Mato Grosso, Cuiabá, MT, Luciano Figueiredo da Universidade Federal da Bahia, Salvador, BA, sobre sua experiência com acidentes ofídicos, todos responderam que nos muitos anos de atividade, em nenhum caso, à base do quadro clínico-patológico, estabeleceram o diagnóstico de acidente ofídico como causa de morte em bovinos.

Riet-Correa (2004) afirmou ainda que acidente ofídico em bovino é raríssimo; viu somente um caso não-fatal de envenenamento botrópico (com necrose no local da picada), em animal que não foi tratado. Lemos (2004) verificou somente um caso não-fatal de acidente ofídico em bovino (por Bothrops). Já Figueiredo (2004) é de opinião que casos não-fatais de acidente ofídico em bovinos não são raros, mas na Bahia observou apenas um caso fatal em bovino suspeito tratar-se de acidente ofídico, com quadro hemorrágico. Não foram realizados exames histopatológicos. Embora Costa (2004) considere que acidentes ofídicos sejam freqüentes em bovinos (haveria inchaço da barbela e da paleta, às vezes escoaria sangue pelas narinas, mas o animal não morreria), viu apenas um único caso de uma vaca da qual suspeitou que tivesse morrido por envenenamento ofídico. Não foi realizada a necropsia. No Estado do Rio de Janeiro, Canella (2004) informa que tem diagnosticado casos de enve- nenamento botrópico em bovinos, caracterizados por edema, geralmente localizado em um membro, e que o tratamento com anti-inflamatórios, anti-histamínicos e antibióticos recupera os animais rapidamente.

\subsection{Nossa Experiência}

Em nossas viagens de estudo e nos trabalhos de diagnóstico de rotina no Setor de Anatomia Patológica do antigo Instituto de Biologia Animal, hoje Convênio "Projeto de Sanidade Animal Embrapa/UFRRJ”, Km 47, em mais de 50 anos, nunca estabelecemos o diagnóstico de morte por acidente ofídico em bovino. Por outro lado, as referências por parte de fazendeiros, vaqueiros e veterinários, à ocorrência e à importância dos acidentes ofídicos, constituiram uma constante nos históricos fornecidos ou obtidos durante essas viagens de estudo, em todo Brasil. À medida que dávamos andamento às investigações, essas suspeitas nunca se confirmaram. As seguintes observações ilustram esse fato:

a) Na Região Amazônica, por ocasião de nossos estudos sobre doenças em bovinos causadas por plantas tóxicas, realizados durante os anos de 1976-1979, que resultaram na elaboração do livro "Plantas Tóxicas da Amazônia a Bovinos e outros Herbívoros" (Tokarnia et al. 1979), iniciávamos nossas investigações pela coleta de históricos. Perguntávamos se casos de intoxicação por plantas seriam freqüentes. As informações prestadas por veterinários, agrônomos, outros técnicos que trabalham no campo e criadores eram bastante uniformes: dizia-se que só ocorriam casos isolados e que as plantas tóxicas não teriam importância como causa de mortes em bovinos. Visitávamos, então, fazendas, onde sempre ocorriam mortandades atribuídas a acidentes ofídicos. Inspecionávamos os pastos, mais minuciosamente os locais onde morriam os animais. Verificamos que, quase sempre, estas áreas eram seriamente invadidas por Palicourea marcgravii (na terra firme) e por Arrabidaea bilabiata (nas várzeas). Os vaqueiros estavam tão convencidos que as mortes eram causadas por picada de cobra que, quando chegávamos perto desses locais, se negavam a prosseguir por medo de cobras, de forma que tínhamos de inspecioná-los sozinho. Hoje sabemos, é na Região Norte que mais morre gado intoxicado por plantas tóxicas no Brasil. Em nenhuma ocasião pudemos diagnosticar ou, pelo menos, suspeitar que tivessem ocorrido mortes em bovinos devidas a acidentes ofídicos.

b) Nas várzeas de fazendas da região dos "lavrados" (cerrado), banhados pelos grandes rios, especialmente o Branco, o Tacutu e o Mucajaí, em Roraima, há elevada incidência de casos de "morte súbita" em bovinos, em especial na época de seca (novembro a abril), quando os animais são movimentados. Nas fazendas ao longo dos rios Uraricoera e Surumu, a incidência dessas mortes é menor. Os criadores culpam uma planta chamada de "tingui" (Coutoubea ramosa) por essas mortes. Através de estudos experimentais, determinamos que não essa planta, mas outra, Arrabidaea japurensis (sem nome popular na região), é a causa dessas mortes. Nessas mesmas regiões ainda são encontrados bovinos mortos sem terem sido submetidos à movimentação, e parte dos criadores, atribui essas mortes à picada de cobra; outros, porém, duvidam dessa afirmativa em virtude do número excessivo de mortes em relação à pequena quantidade 
de cobras que se vê. Somos da opinião que provavelmente $A$. japurensis também seja responsável por grande parte dessas mortes atribuídas a acidentes ofídicos, pois se sabe que, se a quantidade da planta ingerida for suficientemente grande, os animais intoxicados por plantas desse grupo, morrem sem ser exercitados. (Tokarnia \& Döbereiner 1981a,b)

c) Ainda durante os estudos realizados em Roraima para verificar a causa de mortes de bovinos em determinado estabelecimento agropecuário, situado na região dos lavrados, recebemos a informação que em todos os pastos ocorriam mortes ocasionais, ora mais em um, ora mais em outro. $O$ encarregado da pecuária atribuía essas mortes a picadas de cobras (haveria muitas cascavéis na região). Já o administrador geral houve por bem verificar se não tratava de raiva ou intoxicação por plantas. Durante a nossa estada de 12 dias na fazenda, soubemos da morte de oito bovinos, quatro dos quais encontrados mortos, três deles já em putrefação e somente um ainda em condições para a realização de necropsia, apesar da constante procura por animais doentes. Os quatro animais restantes foram encontrados ainda com vida e a doença foi por nós monitorada até a morte dos animais ou o sacrifício em estado agônico. Desses quatro, três apresentaram quadro de botulismo secundário à deficiência de fósforo. No quarto animal, o quadro era diferente e à necropsia verificaram-se numerosos abscessos e fibrose no fígado e um carcinoma volumoso no rúmen. Os exames de laboratório (microfixação de complemento induzida pelo aquecimento, realizados pelo Prof. Iveraldo S. Dutra, Unesp-Araçatuba, SP) confirmaram o diagnóstico de botulismo nos três casos suspeitos. O encarregado da pecuária, que nos acompanhou durante os trabalhos, e inicialmente achava desnecessário o nosso estudo, admitiu: "Para nós, todos esses eram casos de picada de cobra".

d) Por ocasião de outro estudo realizado em 1979 para determinar a causa de mortandade de bovinos em um estabelecimento agropecuário com rebanho de 20.000 cabeças, localizado no município de Luciara, no norte do Estado de Mato Grosso, verificamos, através do livro de registro, que desde a sua implantação, em 1974, morriam em média 2.000 cabeças por ano. As mortes eram atribuídas ao envenenamento ofídico, à ingestão de plantas tóxicas ou a causas desconhecidas, com aproximadamente um terço da incidência para cada uma das pretensas causas. Ao perguntarmos como eram feitos os diagnósticos, fomos informados do seguinte: "Quando a rês morta é encontrada com líquido avermelhado escorrendo pelas narinas, trata-se de acidente ofídico; se sai líquido verde, é caso de intoxicação por planta; e quando não há presença, nem de um, nem de outro líquido escorrendo pelas narinas, então a causa é desconhecida." É evidente que esses "diagnósticos" tinham como base alterações pós-mortais. Verificamos nos pastos desta fazenda grande quantidade de Palicourea marcgravii, a provável causa da mortandade.

\section{DISCUSSÃO E CONCLUSÕES}

A revisão da literatura demonstra que as opiniões dos veterinários sobre a importância dos acidentes ofídicos letais em bovinos, no Brasil, são divergentes. Enquanto alguns acham que são freqüentes (Novaes et al. 1986, Belluomini 1990, Bicudo 1994) (para facilitar, os denominaremos "ofidistas"), outros acreditam que acidentes ofídicos são pouco importantes (Grunert \& Grunert 1969) ou que têm menor importância do que lhes é atribuída (Pacheco \& Carneiro 1932) ou ainda que os acidentes ofídicos seriam esporádicos, geralmente causados por Bothrops (Mendez 2001) ("não-ofidistas"). Há ainda os que são de opinião que se trata de um ponto não-esclarecido (Araujo et al. 1963, Belluomini et al. 1983). Já o homem do campo quase sempre empresta grande importância às picadas de cobra.

Os "ofidistas", aparentemente, apenas se limitam a afirmar que esses acidentes são importantes e a repetir o que dizem os fazendeiros, sem provas, (Novaes et al. 1986, Belluomini 1990, Bicudo 1994). Por exemplo, de acordo com Bicudo (1994), com base em observações de campo de Stefanini (1991), anualmente morreriam 130.000 bovinos picados por cobra no Brasil, porém não há qualquer informação sobre como foram estabelecidos os diagnósticos, o que seria importante, devido às controvérsias e à relevância do assunto.

A revisão bibliográfica revelou o diagnóstico fundamentado de somente dois casos fatais de envenenamento por Bothrops spp em bovinos, e de nenhum por Crotalus spp. No levantamento da situação junto a patologistas e clínicos no Brasil, e em nossos próprios trabalhos de pesquisa e de diagnóstico, não foi estabelecido nenhum diagnóstico comprovado de acidente ofídico fatal em bovinos.

De fato, não é fácil determinar com precisão, até que ponto acidentes ofídicos ocorrem no Brasil. Em relação ao envenenamento botrópico parece razoável acreditar que o diagnóstico não é difícil, se considerarmos a inchação local, associada ao quadro hemorragíparo que ocorre em bovinos (Andrade 2005), de forma que sua ocorrência, provavelmente, não passaria despercebida dos veterinários. Por outro lado, é possível que casos de carbúnculo sintomático ou trauma tenham sido diagnosticados como acidente botrópico. $\mathrm{O}$ aumento do volume que ocorre em massas musculares e/ou tecido celular subcutâneo de bovinos que morrem de carbúnculo sintomático é, muitas vezes, interpretado por criadores, peões e até pelo veterinário como decorrente de picada de cobra. Quando acontece de, mais tarde, após a morte, esse animal ser observado durante a fase em que há saída de líquido sero-sangünolento pelas narinas, boca, ânus ou vulva, isso é tomado como confirmação de que se trata de acidente ofídico. A eliminação dessas secreções constitui apenas parte dos fenômenos pós-mortais (autólise, lise de hemácias) e irá acontecer mais cedo ou mais tarde (sobretudo na dependência da temperatura ambiente), independentemente da causa da morte do animal. Mais ainda, aparentemente, em nosso meio, há a tendência de se associar essas alterações pós-mortais ao carbúnculo hemático, enfermidade rara em nosso meio (Langenegger 1994), que cursa com eliminação de sangue total (e não apenas de líquido tingido de hemoglobina) pelos orifícios naturais, imediatamente após a morte. De qualquer forma, o risco de serpentes do gênero Bothrops determinarem acidentes fatais em bovinos não parece ser elevado, muito pelo contrário, como se verificou nos experimentos de Araujo et al. (1963), os quais evidenciaram que, no Brasil, somente $B$. alternatus (urutu, urutu-cruzeiro) das muitas espécies existentes do gênero Bothrops seria capaz de inocular uma quantidade de veneno suficiente para matar um bovino de $400 \mathrm{~kg}$, considerando a quantidade total de veneno que $75 \%$ das serpen- 
tes fornecem na primeira extração de peçonha. Se examinamos o Quadro 1, contudo podemos verificar que B. jararacussu. B. moojeni e B. cotiara teriam suficiente veneno para causar acidente letal em bovinos com pesos de, respectivamente, 250,255 e $260 \mathrm{~kg}$, se consideramos a quantidade de veneno coletada da serpente que mais produziu veneno.

Porém se levarmos em conta o que interessa, ou seja, na prática, quais serpentes do gênero Bothrops, através da picada (e não da inoculação experimental) foram capazes de matar um bovino, a resposta é: apenas $B$. alternatus (urutu), que matou um de três animais picados (33,3\%); esse animal tinha apenas $279 \mathrm{~kg}$ (Novaes et al. 1986). Dos outros 18 bovinos picados (pelo menos 3 bovinos por cada espécie de serpente, exceção feita a $B$. atrox, que não foi colocada para picar nenhum animal) pelas outras serpentes dos gênero Bothrops, nenhum morreu, mesmo em se tratando de animais com peso abaixo de $300 \mathrm{~kg}$, tratados e não-tratados.

Novaes et al. (1986), em seus experimentos de inoculação do veneno de Bothrops spp, obteve doses letais mais baixas do que as observadas por Araúijo et al. (1963), mas os animais por eles utilizados não se encontravam em boas condições físicas (Novaes 2005).

No que se refere ao envenenamento por Crotalus, a questão é mais complicada. Animais picados por Crotalus spp podem mostrar um quadro clínico de difícil interpretação, com o agravante de, em geral, ser de rápida evolução e não cursar com lesão macroscópica visível. Por exemplo, esses acidentes podem mimetizar, em muitos aspectos, o quadro sintomatológico verificado em casos de botulismo ou serem confundidos com os observados em doenças que cursam com distúrbios neurológicos sem alterações da psique, ou mesmo com as que são determinadas por incapacitação muscular difusa. De acordo com os experimentos de Araujo et al. (1963), as cobras do gênero Crotalus podem produzir e armazenar quantidades suficientes de veneno para matar um bovino de $1.000 \mathrm{~kg}$ (no trabalho original, por um erro de cálculo, os autores consideram esse valor como $2.000 \mathrm{~kg}$ ). Nesse ponto, porém, não se pode perder de vista o que ocorre sob condições naturais, isto é, quanto de veneno uma cascavel realmente inocularia ao picar um bovino. Embora seja impossível determinar caso a caso esse valor (ver 1.6) é fundamental levar em consideração que muitas picadas (10-42\%) de Crotalus são "secas" (Silveira \& Nishioka 1995, Rezende et al.1998) ou que apenas pequena parte do veneno armazenado na glândula estaria sendo injetada, como no caso de Vipera palestinae que, em média, injeta apenas $8 \%$ do veneno que está armazenado (Allon \& Kochva 1976). Por outro lado, como o local da picada é praticamente imperceptível, casos fatais e não-fatais de envenenamento crotálico poderiam ocorrer e passar despercebidos. Determinar se esses casos são ou não freqüientes é problemático. A verificação visual de um grande número de serpentes desse gênero em uma determinada área, associada à ocorrência de mortes de animais que tenham apresentado quadro clínico compatível, pode ser sugestiva. Mesmo nessa situação é necessário descartar a possibilidade de tratar-se de outras enfermidades que cursam com quadro clínico e evolução semelhantes. A inoculação de veneno crotálico, por via sucutânea em 8 bovinos, resultou em necrose [hialinização] de miócitos em todos os dez músculos esqueléticos examinados histologicamente [língua, masseter, diafragma, intercostal, cervical, bíceps, psoas, longodorsal, semimembranoso e semitendinoso distantes do local de aplicação e não submetidos à pressão por decúbito] (Graça 2005). Ao nosso ver, essa lesão pode ser um bom indicativo de envenenamento crotálico, se considerada em associação com os aspectos epidemiológicos e clínicos. Esse tipo de necrose não é difuso na musculatura, e sim ocorre em fibras isoladas uma da outra ou em pequenos grupos de fibras.

Esse levantamento torna claro que é preciso melhor investigar, por meio de diagnósticos mais precisos, as mortes suspeitas de terem sido causadas por acidente ofídico em bovinos no Brasil. O diagnóstico de acidente ofídico deve, como no caso de outras doenças, ser estabelecido através do maior número possível de dados, sobretudo o histórico, o exame clínico e a necropsia, complementada por exames histopatológicos. Também o conhecimento de dados sobre o habitat e a distribuição de nossas serpentes venenosas certamente contribui para estabelecer, de forma mais acurada, a importância de acidentes ofídicos para animais domésticos em cada Região ou área. Por exemplo, levandose em conta esses aspectos, pode-se concluir que acidentes ofidicos por Crotalus spp na Região Amazônica são limitados aos campos abertos de Humaitá, Serra do Cachimbo e Santarém (Melgarejo 2003). Na Amazônia também não existe B. alternatus, a serpente do gênero Bothrops com maior potencial de letalidade (Melgarejo 2003). Esses dados indicam que dificilmente ocorrem acidentes ofídicos fatais em bovinos adultos na Amazônia, a não ser nas microrregiões acima mencionadas onde existe Crotalus. É curioso observar que é justamente na Região Amazônica que as serpentes são mais responsabilizadas por mortes de bovinos.

É necessário ainda estar atento para os diagnósticos diferenciais, especialmente com carbúnculo hemático, carbúnculo sintomático, intoxicação por plantas (sobretudo as causadas por plantas que causam "morte súbita” e plantas cianogênicas), botulismo e outras doenças que cursam com paralisia motora, inclusive raiva, e deficiência de cobre - "falling disease".

Um outro aspecto a ser considerado, diz respeito às diferenças e controvérsias sobre quadros clínico-patológicos observados em diversas espécies. Em relação ao veneno crotálico, no homem, macroscopicamente, há mioglobinúria, que tem sido relacionada a um efeito miotóxico do veneno crotálico. Nos bovinos, porém, não se verifica essa alteração na urina (Birgel et al. 1983, Graça 2005), embora haja evidências histológicas de necrose focal de fibras musculares. A observação mais cuidadosa das lesões musculares verificadas em 8 bovinos envenenados experimentalmente com veneno crotálico, não revela lise, apenas necrose, de fibras musculares esqueléticas nos bovinos, o que poderia explicar a ausência de mioglobina na urina (Graça 2005). Suscita dúvidas, porém, a questão do porque a necrose coagulativa não é mais marcada no local da picada, se aí o veneno está mais concentrado. Seria interessante verificar se essa necrose teria ou não correlação com hipoperfusão periférica (ou o aumento da pressão compartimental dentro dos músculos), como tem sido demonstrado nas rabdomiólises dos eqüinos que ocorrem em função da hipotensão anestésica, ou se é simplesmente uma questão de maior sensibilidade das fibras lesadas, como indicam Azevedo-Marques et al. (2003).

Por outro lado, também é fundamental que se investigue até que ponto o veneno crotálico realmente teria ação nefrotóxica 
ou se as lesões renais refletem, parcial ou totalmente, apenas o efeito do choque sobre o órgão. De qualquer maneira, na literatura há dados de difícil interpretação ou controversos em relação a esse órgão. Por exemplo, como o envenenamento crotálico poderia induzir à diminuição da concentração da urina e, ao mesmo tempo, proteinúria e glicosúria?

Diferenças maiores há nas alterações histológicas. A necrose hialina na parede das arteríolas do pulmão e do sistema nervoso central, descrita por Saliba et al. (1983) na intoxicação crotálica em bovinos, não foi verificada por nenhum outro autor. Da mesma forma, a presença de trombos hialinos na luz de arteríolas e de capilares pulmonares descrita por Saliba et al. (1983) na intoxicação crotálica em bovinos, não foi observada por Amorim et al. (1951) em animais de laboratório e cães experimentais. Nesses últimos, Amorim et al. (1951) encontraram trombos hialinos nos capilares pulmonares, só na intoxicação por Bothrops - nunca ocorreu no grupo com veneno crotálico. Amorim et al. (1951) concluem que esta lesão até poderia ser usada no diagnóstico diferencial com o envenenamento por Crotalus. No que tange à morfologia das alterações renais, há pontos, no mínimo, obscuros. Por exemplo, como descartar que a glomerulonefrite focal observada em $31 \%$ dos animais (Saliba et al. 1983) não seria incidental, já que esse tipo de lesão é relativamente comum em bovinos. Também é algo questionável a velocidade que apareceram essas lesões, dada à evolução, em geral, muito rápida do envenenamento. Outras alterações, pela forma que foram descritas, nos parecem difíceis de diferenciar de fenômenos autolíticos. As lesões musculares descritas por Lago (1996) estão de acordo com o que é relatado para o homem e animais de laboratório, porém este autor não menciona alterações renais.

No que se refere ao envenenamento botrópico verificado no homem e nos animais, não há divergências significativas em relação ao quadro clínico-patológico, porém, a natureza e patogênese das lesões renais associadas a esse tipo de envenenamento deveriam ser melhor estudadas.

Em decorrência das controvérsias acima mencionadas e dos pontos a serem melhor esclarecidos e, ainda, em função da conhecida variação do efeito dos venenos em diferentes espécies animais, se impõe a realização de experimentos em bovinos para a obtenção desses dados.

Com base nos dados disponíveis e em nossa experiência, somos da opinião que os acidentes ofídicos fatais em bovinos são bem menos freqüientes do que se acredita, isto é, sua importância vem sendo bastante superestimada.

\section{REFERÊNCIAS}

Allon N. \& Kochva E. 1976. The quantities of venom injected into prey of different size by Vipera palaestinae in a single bite. J. Exp. Zool. 188:71-76.

Amaral C.F.S. \& Rezende N.A. 1994. Tratamento das complicações dos acidentes por animais peçonhentos, p.345-372. In: B. Barraviera (ed.) Venenos. Venenos Animais. Uma Visão Integrada. Editora de Publicações Científicas (EPUC), Rio de Janeiro.

Andrade S.C. 2005. Tese de Mestrado em elaboração, Curso de Pós-Graduação em Ciências Veterinárias, Universidade Federal Rural do Rio de Janeiro.

Anônimo 2004. Prevenção contra cobras. Veja 37(16):112.
Amorim M.F., Mello R.F. \& Saliba F. 1951. Envenenamento botrópico e crotálico. Mem. Inst. Butantan 23:63-108.

Araujo P. \& Belluomini H.E. 1960-1962. Toxicidade de venenos ofídicos. I. Sensibilidade específica de animais domésticos e de laboratório. Mem. Inst. Butantan 30:143-156.

Araujo P., Rosenfeld G. \& Belluomini H.E. 1963. Toxicidade de veneneos ofídicos. II. Doses mortais para bovinos. Arqs Inst. Biológico, São Paulo, 30:43-48.

Azevedo-Marques M.M., Hering S.E. \& Cupo P. 2003. Acidente crotálico, p.91-98. In: Cardoso J.L.C., França F.O.S., Wen F.H., Málque C.M.S \& Haddad Jr.V. (ed.) Animais Peçonhentos no Brasil, Biologia, Clínica e Terapêutica dos Acidentes. Sarvier Editora., São Paulo.

Barraviera B. 1994. Acidentes por serpentes dos gêneros "Crotalus" e "Micrurus", p.281-295. In: Barraviera B. (ed.) Venenos Animais, uma Visão Integrada. EPUC, Rio de Janeiro.

Barraviera B. 1999. Ofídios, Estudo Clínico dos Acidentes. Editora de Publicações Biomédicas, Petrópolis, 46p.

Barraviera B. \& Pereira P.C.M. 1994. Acidentes por serpentes do gênero "Bothrops", p.261-280. In: Barraviera B. (ed.) Venenos Animais, uma Visão Integrada. EPUC, Rio de Janeiro.

Belluomini H.E. 1976. O que se deve saber sobre serpentes. Noticioso Rhodia-Mérieux, 5(52):6-16.

Belluomini H.E. 1990. Envenenamento botrópico experimental em bovinos. Projeto de Pesquisa (CNPq), São Paulo.

Belluomini H.E., Araujo P., Rosenfeld G., Leinz F.F. \& Birgel E.H. 1982. Symptomatologie der experimentellen Crotalustoxin-Vergiftung bei Rindern, die einer spezifischen Serumtherapie unterworfen wurden. Dtsch. Tierärztl. Wschr. 89(11):444-448.

Belluomini H.E., Araujo P., Rosenfeld G. \& Penha A.M. 1983. Beitrag zur Serumtherapie bei experimenteller Vergiftung von Rindern mit dem Gift der Klapperschlange. Dtsch. Tierärztl.Wschr. 90:93-95.

Bicudo P.L. 1994. Acidentes ofídicos em Medicina Veterinária, p.375-387. In: Barraviera B. (ed.) Venenos Animais, uma Visão Integrada. EPUC, Rio de Janeiro.

Bicudo P.L. \& Biondo A.W. 1989. Acidentes ofídicos atendidos no Hospital Veterinário da FMVZ, Unesp-Botucatu, SP, no período de 1972-1989. Estudo retrospectivo (Não publicado). (Cit. Bicudo 1994)

Birgel E.H., Belluomini H.E. \& Leinz F.F. 1983. Auswertung der Urinbefunde bei Rindern mit experimenteller Crotalus-Vergiftung. Zbl. Vet. Med. A 30:283-289.

Borges R.C. 1999. Serpentes Peçonhentas Brasileiras. Manual de Identificação, Prevenção e Procedimentos em Caso de Acidentes. Atheneu, São Paulo.

Canella C.F.C. 2004. Comunicação pessoal (Med. Vet. do Min.Agricultura, Vassouras, RJ).

Clarke E.G.C. \& Clarke M.L. 1969. Snakes and snakebite. Vet. Ann. 10:2748.

Christensen P.A. 1968. The venoms of Central and South African snakes, p.437-461. In: Bücherl W. \& Buckley E.E. (ed.) Venomous Animals and their Venoms. Vol.1. Venomous Vertebrates. Academic Press, New York.

Costa J.B.D. 2004. Comunicação pessoal (Diretor Técnico da Empaer, Cuiabá, MT).

Figueiredo L.J.C. 2004. Comunicação pessoal (UDAB, Universidade Federal da Bahia, Salvador, BA).

Fonseca F. 1949. Animais Peçonhentos. Empresa Gráfica da Revista dos Tribunais, São Paulo. 376p. (Cit. Bicudo 1994)

França F.O.S. \& Málaque C.M.S. 2003. Acidente botrópico, p.72-86. In: Cardoso J.L.C., França F.O.S., Wen F.H., Málque C.M.S \& Haddad Jr V. (ed.) Animais Peçonhentos no Brasil, Biologia, Clínica e Terapêutica dos Acidentes. Sarvier Editora, São Paulo.

Graça F. 2005. Tese de Doutorado em elaboração. Curso de Pós-Graduação em Ciências Veterinárias, Universidade Federal Rural do Rio de Janeiro. 
Grunert E. 1967. Beobachtungen über Schlangenbissverletzungen bei grossen Haustieren in Süd-Brasilien. Dtsch. Tierärztl. Wschr. 74(20):531-532.

Grunert E. \& Grunert D. 1969. Beobachtungen von "Bothrops"Schlangenbissverletzungen bei Rind und Pferd in Rio Grande do Sul, Brasilien. Vet.-Med. Nachrichten, Bayer, 1969, Heft 3:217-232.

Habermehl G, 1977. Gift-Tiere und ihre Waffen. 2. Auflage. Springer Verlag, Berlin.

Humphreys D.J. 1988. Veterinary Toxicology. 3rd ed. Baillière Tindall, London.

Lago L.A. 1996. Avaliação clínica e laboratorial de bovinos submetidos ao envenenamento crotálico experimental - Crotalus durissus terrificus Laurenti, 1768 - Crotamina positivo. Tese de Mestsrado, Escola de Veterinária, Universidade Federal de Minas Gerais, Belo Horizonte. 62p.

Langenegger J. 1994. Ocorrência do carbúnculo hemático em animais no Brasil. Pesq. Vet. Bras. 14(4):135-136.

Lemos R. 2004. Comunicação pessoal (Depto Med. Preventiva, Universidade Federal de Mato Grosso do Sul, Campo Grande, MS).

Málaque C.M.S.A. \& França F.O.S. 2003. Acidente Laquético, p.87-90. In: Cardoso J.L.C., França F.O.S., Wen F.H., Málque C.M.S \& Haddad Jr V. (ed.) Animais Peçonhentos no Brasil, Biologia, Clínica e Terapêutica dos Acidentes. Sarvier Editora, São Paulo.

Melgarejo A.F. 2003. Serpentes Peçonhentas do Brasil, p.33-61. In: Cardoso J.L.C., França F.O.S., Wen F.H., Málque C.M.S \& Haddad Jr V. (ed.) Animais Peçonhentos no Brasil, Biologia, Clínica e Terapêutica dos Acidentes. Sarvier Editora, São Paulo.

Melgarejo A.F. 2005. Comunicação pessoal (Divisão de Animais Peçonhentos, Instituto Vital Brasil, Niterói, RJ).

Méndez M.C. 2001. Envenenamento botrópico, p.169-176. Riet-Correa F., Schild A.L., Méndez M.C. \& Lemos R.A.A. (ed.) Doenças em Ruminantes e Eqüinos. Vol.2. 2a ed. Varela Editora, São Paulo.

Menezes R.V. 1995/96. Ofidismo em bovinos. Arq. Esc. Med. Vet., Salvador, 18(1):224-231.

Mosmann M.N. 2001. Guia das Principais Serpentes do Mundo. Vol.2. Editora ULBRA, Canoas, RS.

Novaes A.P. 2005. Comunicação pessoal (Embrapa, UEPAE São Carlos, SP).

Novaes A.P., Lucas S., Abe A.S., Fernandes W., Puorto G. \& Almeida I.L. 1986. Envenenamento botrópico em bovinos: tratamento opcional. Circular Técnica no.3, Embrapa, UEPAE São Carlos, SP. 29p.

Ollhoff R.D. 2005. Comunicação pessoal (Pontifícia Universidade Católica do Paraná, Curitiba, PR).

Oliveira N.J.F., Melo M.M., Ribeiro E.L., Lago L.A. \& Lucia M. 2004a. Achados histopatológicos em bovinos experimentalmente envenenados com veneno de Bothrops alternatus. XXXI Conbravet, São Luiz, MA. (Resumo)
Oliveira N.J.F., Ribeiro E.L., Silva J. P.G.P., Lago L.A., Lucia M. \& Melo M.M. 2004b. Bovine blood profile after Bothrops alternatus envenomation. VIII Congr. Soc. Bras. Toxinologia, Angra dos Reis, RJ. (Resumo)

Pacheco G. \& Carneiro V. 1932. Estudos experimentais sobre plantas tóxicas. I. Intoxicação dos animais pela "erva de rato da mata". Revta Soc. Paulista Med. Vet. 2(2-3):23-46.

Rezende N.A., Torres F.M., Dias M.B., Campolina D., Chaves-Olortegui C. \& Amaral C.F.S. 1998. South American rattlesnake bite (Crotalus durissus sp) without envenoming: insight on diagnosis and treatment. Toxicon 36(12):2029-2032.

Riet-Correa F. 2004. Comunicação pessoal (Centro de Saúde e Tecnologia Rural, Universidade Federal de Campina Grande, Campus de Patos, PB).

Rosenfeld G. 1971. Symptomatology, pathology and treatment of snake bites in South America, p.345-384. In: Bücherl W. \& Buckley E.E. (ed.) Venomous Animals and their Venoms. Volume 2. Venomous Vertebrates. Academic Press, New York.

Rosenfeld G. \& Belluomini H.E. 1960. Quantidades de veneno encontrado em serpentes venenosas do Brasil. Dados comparativos para avaliação da mortalidade humana (Resumo). I. Congr. Bras. Zoologia, Museu Nacional, Rio de Janeiro. (Cit. Belluomini 1976)

Saliba A.M., Belluomini H.E. \& Leinz F.F. 1983. Experimentelle CrotalusVergiftung bei Rindern, anatomisch-pathologische Studie. Dtsch. Tierärztl. Wschr. 90:513-517.

Silveira P.V. \& Nishioka S.E. 1995. Venomous snake bite without clinical envenoming ("dry bite”). A neglected problem in Brazil. Trop. Geogr. Med. 47(2):82-85. (Abstract in PubMed)

Soroensen B. 1990. Animais Peçonhentos. Atheneu, Rio de Janeiro.

Stefanini D.L. 1991. Estatística de mortalidade em sete fazendas localizadas nos municípios de São Manuel, Presidente Alves, Botucatu, Anhembi e Bento de Abreu, no período de 1973 a 1991 (Dados não publicados). (Cit. Bicudo 1994)

Stöber M. 2002. Giftschlangenbiss, p.1276-1278. In: Dirksen G., Gründer H.-D. \& Stöber M. (ed.) Innere Medizin und Chirurgie des Rindes. 4.Aufl. Parey Verlag, Berlin.

Tokarnia C.H., Döbereiner J. \& Silva M.F. 1979. Plantas Tóxicas da Amazônia a Bovinos e outros Herbívoros. INPA, Manaus. 95p.

Tokarnia C.H. \& Döbereiner J. 1981a. Intoxicação por Arrabidaea japurensis (Bignoniaceae) em bovinos em Roraima. Pesq. Vet. Bras. 1(1):7-17.

Tokarnia C.H. \& Döbereiner J. 1981b. Intoxicação experimental por Coutoubea ramosa (Gentianaceae) em bovinos. Pesq. Vet. Bras. 1(2):5560 .

Tokarnia C.H., Döbeiner J. \& Peixoto P.V. 2000. Plantas Tóxicas do Brasil. Editora Helianthus, Rio de Janeiro. 310p. 